\title{
ЭКОНОМИКО-МАТЕМАТИЧЕСКАЯ МОДЕЛЬ ИНВЕСТИЦИОННОГО ПРОЕКТА ДЛЯ МОДЕРНИЗАЦИИ ПРЕДПРИЯТИЙ ЧЕЧЕНСКОЙ РЕСПУБЛИКИ
}

\author{
Илаева 3.М. ${ }^{1}$, \\ Алихаджиева Д.Ш. \\ ${ }^{1}$ Чеченский государственный университет, г. Грозный, Россия \\ 2 ГГНТУ имени акад. М. Д. Миллионщикова, г. Грозный, Россия
}

В рамках разработки теорий и методологий экономического $и$ математического моделирования рассматриваются возможности сферы применения, а также теоретические методологические вопросы по улучиению сочииально-экономического процесса проектирования и развития инвестиционного проектирования. Данная статья посвящена исследованию экономико-математических моделей инвестиционных проектов. В настоящее время в контексте принятия управленческих решений разработаны комплексные $и$ системные методы $и$ модели оценки эфффективности инвестиционных проектов. В статье дается анализ современного состояния инвестиционной деятельности в Чеченской республике, это дает возможность оценить эффективность проекта на основе применения методов экономико-математического моделирования в модернизации промылиленных предприятий.

Ключевые слова: инвестиционный проект, экономико-математическая модель, предприятия, регион, управление.

Необходимым условием устойчивого развития регионов и в целом российской экономики является реализация инвестиционных проектов [7]. Одним из наиболее актуальных вопросов теории управления инвестиционным процессом является оценка эффективности инвестиционных проектов, совместно осуществляемых организацией.

Принятие решений о целесообразности реализации инвестиционных проектов для создания малых и средних производственных предприятий во многом зависит от выбора методов оценки их эффективности и использования существующих множество методов, которые могут повысить качество принимаемых решений $[1,2]$.

В этих методах можно выделить экономико-математические модели, и с их помощью можно решить технические задачи, такие как определение масштаба, состава компонентов и местоположения проекта.

Экономико-математическая модель представляет собой математическую форму, которая централизованно представляет наиболее важные отношения и модели поведения управляемой системы. 
Модели инвестирования играют важную роль в теории воспроизводства капитала, оценке компаний, активов, принятии управленческих решений о том, как развивать бизнес компании, и решении многих других экономических проблем, с помощью установления порядка предоставления и отбора инициаторов, которые желают получить помощь государства для развития проекта, а так же утверждает макет бизнес-плана проекта, который предоставляют предприятия.

Методы экономико-математического моделирования могут также использоваться для анализа взаимодействия экономики и окружающей среды [5].

В Чеченской Республике за счет прямой бюджетной поддержки, внебюджетных источников финансирования и при помощи госкомпаний реализуются крупные проекты в сфере промышленности [8].

В этих целях планируется реализация 11 инвестпроектов, таких как:

1. «Организация производства современной приводной техники».

2. «Развитие производства импортозамещающей продукции ГУП «Оргтехника».

3. Программа выпуска продукции ГУП «Опытный завод Минпрома». Плюс».

4. «Организация производства приборов учета на базе ООО «Энергия

5. «Организация производства светодиодных осветительных приборов».

6. Организация производства медицинских инструментов и изделий.

7. «Строительство и запуск завода по выпуску быстромонтируемых опор на композитных стойках» и др.

С общим объемом финансирования 5 665,3 млн. руб.

Расчет точки безубыточности, а также запас финансовой прочности, представлены в таблице 1.

Таблица 1 - Расчет точки безубыточности по инвестиционному проекту в Чеченской Республике, руб.

\begin{tabular}{|l|l|l|l|l|l|l|l|}
\hline Показатель & 1 & 2 & 3 & 4 & 5 & 6 & 7 \\
\hline $\begin{array}{l}\text { Выручка от } \\
\text { реализации }\end{array}$ & 0 & 364539 & 446375 & 446375 & 409177 & 446375 & 409177 \\
\hline $\begin{array}{l}\text { Переменные } \\
\text { издержки }\end{array}$ & 12356,4 & 138210 & 154601 & 163280 & 163508 & 163385 & 160274 \\
\hline $\begin{array}{l}\text { Постоянные } \\
\text { издержки }\end{array}$ & 82379,6 & 921405 & 103067 & 108853 & 109005 & 108923 & 106849 \\
\hline $\begin{array}{l}\text { Маржинальный } \\
\text { доход }\end{array}$ & $-12356,4$ & 226328 & 291773 & 283094 & 245668 & 282989 & 248902 \\
\hline $\begin{array}{l}\text { Доля переменных } \\
\text { затрат }\end{array}$ & 0,6 & 0,6 & 0,6 & 0,6 & 0,6 & 0,6 & 0,6 \\
\hline
\end{tabular}




\begin{tabular}{|l|l|l|l|l|l|l|l|}
\hline $\begin{array}{l}\text { Точка } \\
\text { безубыточности }\end{array}$ & & 148407 & 157679 & 171637 & 181555 & 171811 & 175653 \\
\hline $\begin{array}{l}\text { Запас фин. } \\
\text { прочности }\end{array}$ & - & $-0,59$ & 0,65 & 0,62 & 0,56 & 0,62 & 0,57 \\
\hline $\begin{array}{l}\text { Чистая прибыль } \\
\text { Производственный } \\
\text { рычаг }\end{array}$ & - & 1,03 & 1,29 & 1,20 & 1,03 & 1,20 & 1,06 \\
\hline
\end{tabular}

Маржинальный доход - это разница между суммой переменных затрат и суммой постоянных затрат, осуществляемых при реализации проекта, который показывает вклад предприятия в покрытие постоянных затрат и получение прибыли. Как мы видим, по полученным результатам расчета маржинальный доход предприятия ежегодно увеличивается, среднегодовой прирост за восемь лет равен $17,9 \%$ от уровня года начала реализации проекта.

Так как для расчета точки безубыточности в натуральном выражении необходимы данные об уровне производства (реализации услуг) в натуральном выражение, мы рассчитаем точку безубыточности в целом по реализуемому проекту в стоимостном выражении. Для этого воспользуемся формулой:

$$
\text { Tб }=\frac{\Pi 3}{1-\text { Упеs }}
$$

где, Тб - точка безубыточности в стоимостном выражение;

ПЗ - сумма постоянных затрат по проекту;

$\mathrm{У}_{\text {ПЕз }}$ - доля переменных затрат в выручке от реализации.

При реализации проекта точка безубыточности реализуемого проекта будет достигнута уже во второй год реализации проекта и составит 4840757 руб.

Производственный рычаг - это показатель отражающий взаимосвязь выручки от продаж предприятия, маржинального дохода и прибыли от основной деятельности. Для расчета можно использовать формулу:

$$
\Pi p=\frac{\text { Мू }}{\text { 피 }}
$$

где, Пр - это производственный рычаг;

МД - маржинальный доход;

ЧП - чистая прибыль.

Как мы видим, при изменении выручки от реализации на 1 \% чистая прибыль по проекту предприятия изменится в три раза. 
Результаты формул отражаются на графике: Суммарный объем произведенной продукции, в ходе модернизации предприятий с применением экономико-математической модели.

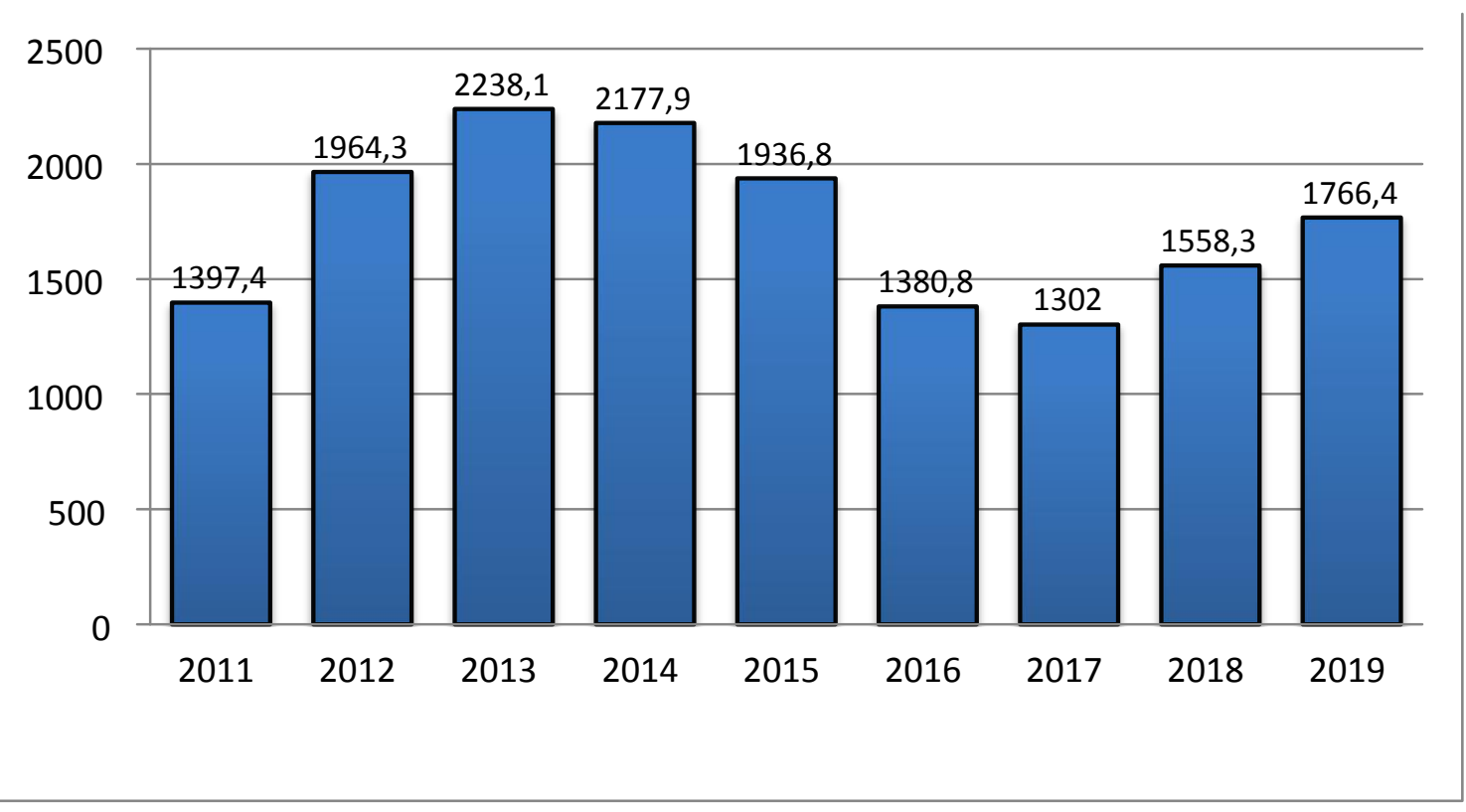

Рис. 1- Суммарный объём производства продукции

В общем, можно сделать вывод, что учитывается влияние реализации проекта реконструкции и технологического перевооружения на эффективность деятельности и темпы развития предприятия, что положительно повлияет на рост экономического состояния Чеченской Республики. Предлагаемый подход к экономико-математическому моделированию инвестиционных проектов для модернизации предприятий может найти отражение при обосновании и реализации проектов пространственного развития Чеченской Республики [6].

\section{Исследование выполнено при финансовой поддержке РФФИ в рамках научного проекта №19-010-00665.}

\section{Список литературы}

1. Алихаджиева Д. Ш. О классификации инвестиционных экологоориентированных проектов в управлении природопользованием // Горизонты экономики. 2019. №6(52). С. 75-79.

2. Алихаджиева Д.Ш. Илаева 3.М., Асхабов Р.Ю. Строительство мини гидроэлектростанций как фактор устойчивого экономического развития региона // Стратегии и инструменты экологически устойчивого развития экономики: сборник трудов XV межд. научно-практ. конф. Российского общества экологической экономики. - Ставрополь : АГРУС Ставропольского гос. аграрного ун-та, 2019. - С. 291-295.

3. Асхабов, Р.Ю., Садыков Х. С.-С., Алихаджиева Д.Ш. Инвестиционностроительный комплекс Чеченской Республики в контексте социальных и 
экологических аспектов устойчивого развития // Стратегии и инструменты экологически устойчивого развития экономики: сборник трудов XV межд. научно-практ. конф. Российского общества экологической экономики. Ставрополь : АГРУС Ставропольского гос. аграрного ун-та, 2019. - С. 158-164.

4. Кошелев В. М., Шушкина Л.В. Комбинированное применение методов проектного анализа и экономико-математического моделирования для определения эффективности инвестиционных проектов // Экономические науки. 2014. - № 24. - С. 80-89.

5. Потравный И.М., Зоидов К.Х. Моделирование эколого-экономических процессов на основе применения функций негативного воздействия на окружающую среду// Экология. Экономика. Информатика. Материалы XL конференции «Математическое моделирование в проблемах рационального природопользования». - Ростов-на-Дону: Изд-во Южного федерального университета, 2012. С. 424-429.

6. Управление проектами пространственного развития : Учебное пособие / Под общ.ред. Комова Н.В., Цыпкина Ю.А., Носова С.И. - М.: ИП Осьминина Е.О. 2020. - 540 с.

7. Яшалова Н.Н. Генезис и перспективы развития концепции устойчивого развития // Экономика природопользования. - 2016. - №2. - С. 4 18.

8. Министерство промышленности и энергетики Чеченской Республики [Электронный pecypc]. Режим доступа: http://minpromchr.ru/subordinateenterprises. (дата обращения: 12.06.2020). 